\title{
EDGE 2013 Program - A Redesign Work in Progress
}

\section{Dr. Dan G. Dimitriu, San Antonio College}

DAN G. DIMITRIU is a licensed Professional Engineer that holds a M.S. and a Ph.D. in Engineering and an M.B.A. in International Economic Relations. He has been practicing engineering internationally since 1970 in various industries and taught engineering courses concurrently for more than 20 years at various institutions. In 2001, he joined San Antonio College full-time as the Coordinator of its Engineering Program. He has been involved with several engineering societies and became a member of the Two-year College Division of ASEE in 2002. His research interests are in renewable energy, plastics, robotics, and engineering education.

\section{Prof. Jerry O’Connor, San Antonio College}

Jerry O'Connor has been teaching physics (along with a few engineering and math) courses since 1980. He is currently Department Chairperson, and has persistently promoted and supported the integration of findings from physics and engineering education research with education practice. 


\title{
EDGE 2013 Program - A Redesign Work in Progress
}

\begin{abstract}
This paper presents a very brief description and history of the EDGE (Early Development of General Engineering) Summer Bridge Program that was initiated in 2003 and focuses on the latest iteration of the program. This project was initially supported by a grant from the National Science Foundation and more recently by grants from Department of Education.

At first the program was intended for well-prepared high school students in the $10^{\text {th }}$ and $11^{\text {th }}$ grades who would have participated in the San Antonio Pre-freshman Engineering Program (PREP) while in middle school. EDGE was designed to pick up where PREP left off by introducing them to college level course work as a learning community and providing activities to help them develop independent learning and teamwork skills with the goal of increasing their likelihood of earning a college degree in engineering, science, math, or other related field. The original courses offered were Introduction to Engineering and College Algebra.
\end{abstract}

After continuing efforts to create a stable sustained program did not bear fruit, a comprehensive examination and redesign of the program was conducted for 2013. The new version would be developed as a two year program. The first year would prepare students for College Algebra by boosting their Math proficiency and helping them acquire a strong college student identity. The second year would introduce them to college level Engineering.

For the 2013 edition of the program we offered only the first year component, with the intent of offering both components the following year, for returning students as well as the new ones. The robotics project, which had become very popular with students, was refined and diversified to include two sequential years of activities and challenges. This enhancement provides increased opportunity for our students to diversify their design and programming skills.

The paper presents rationales for modifications and provides a detailed analysis of the program results along with the planned developments for the 2014 EDGE Program.

\section{Brief History of the Program}

The EDGE Program was started in $2003^{1}$ and initially was intended to continue the work started in the established San Antonio Pre-freshman Engineering Program (PREP) ${ }^{2}$ with a more intense focus on the Engineering profession. From the beginning its stated mission was: "The Early Development of General Engineering (EDGE) Program is designed to increase high school students' awareness of various engineering fields and sustain their interest in the study of engineering. We recognize that Math is critical in the field of engineering; therefore, our program focuses on increasing students' math abilities so they leave our program with the knowledge, skills, and confidence that will prepare them for successful engineering careers."

Despite the excellent reviews our program received from students, parents, and teachers, the expected enrollment numbers did not materialize as expected and the following years $3,4,5,6,7$ brought changes and new developments designed to adapt the program to the needs of a different student population than it was originally intended for and maintain its attractiveness.

Every year the goal was, and still is, to enroll approximately 50 students in two parallel sections. Since the program was initiated in 2003 , there have only been two years when we had more than 
one section. Since the desired student numbers did not materialize, we began making changes that we thought would make the program more appealing without sacrificing rigor. The greatest challenge has consistently been to find a way to accommodate students who were interested in the program but not prepared for College Algebra. The next program iterations included Introduction to Computing and then Introductory Physics as substitutes, along with self-paced computer-based math enrichment programs such as Plato. The substitute courses did not provide transferable credits (for STEM degrees) however, and as enrollments remained flat we continued to seek new program innovations. One of the annual modifications that turned out to be very popular was a robotics project. This element has become a permanent fixture of the program.

During this period a multitude of engineering summer bridge programs were introduced in almost every school across the country and in our area $8,9,10,11$. The students had multiple choices to spend their summers and enrollment reflected these competing options.

Since inception the overall mission of the program has remained the same while specific components have been transformed to reflect the changing needs of our student population. A brief review of the academic accomplishments of participating students in previous EDGE programs as reported by National Student Clearinghouse in December 2012 is shown in Table 1.

\begin{tabular}{|l|c|c|c|c|c|c|c|}
\hline $\begin{array}{l}\text { Education } \\
\text { Level }\end{array}$ & $\begin{array}{c}\text { Enrolled } \\
\text { in EDGE }\end{array}$ & $\begin{array}{c}\text { Not in } \\
\text { Records }\end{array}$ & $\begin{array}{c}\text { Enrolled in } \\
\text { a 2 Year } \\
\text { College }\end{array}$ & $\begin{array}{c}\text { Graduated } \\
\text { with } \\
\text { Associate } \\
\text { Degrees }\end{array}$ & $\begin{array}{c}\text { Enrolled in } \\
\text { a 4 Year } \\
\text { University }\end{array}$ & $\begin{array}{c}\text { Graduated } \\
\text { with a } \\
\text { Bachelor }\end{array}$ & $\begin{array}{c}\text { Graduated } \\
\text { with a } \\
\text { Master's } \\
\text { Degree }\end{array}$ \\
\hline \# Students & 228 & 29 & 61 & 23 & 85 & 47 & 2 \\
\hline
\end{tabular}

Table 1. Academic Accomplishments of Past EDGE Students

The 29 students that were unaccounted for are to be considered out of the system or still in high school. Of all the students that had obtained a degree, $61 \%$ of them received degrees in a technical field. The numbers do not necessarily add up because several students earned more than one degree, or after earning their associate transferred to a four years institution.

\section{Changes made in 2013}

All students entering the college are required to take an assessment test to determine their readiness for college level work. From the beginning of our program this test has been the Accuplacer $^{\circledR}$, supplied by The College Board. The student placement scores for mathematics have spanned a broad range, with the largest fraction in the developmental levels. Since this was an ongoing problem that restricted enrollment in the Introduction to Engineering course, a concerted effort was made to address the "mathematics deficit" in 2013.

A series of discussions was initiated among members of the EDGE program committee, faculty, and members of the Math Department to formulate a new approach that could focus on introducing the Engineering profession while building mathematics skills. Some direction was provided by examining the role of Math in engineering education ${ }^{12}$ as well as by the empirical evidence provided by two reports which suggest that the length of time students spend in developmental education courses relates negatively to degree completion ${ }^{13,14}$. This led us to affirm a strong emphasis on boosting students' Math performance beyond developmental stages. Several 
studies together with a rigorous one by National Center for Postsecondary Research provide the strongest evidence to date on the effectiveness of developmental summer bridge programs ${ }^{15,16,17 \text { and }}$ 18. If we can find a way to minimize the time spent by the students in remedial math and do it in a way that brings to life the use of Math in the real world and, particularly, engineering applications, we can accomplish our mission in multiple ways. First, we may be able to dispel the proverbial "fear of Math" by demonstrating the intrinsic connection of Math with everyday problems. Then, we can show the students how engineers use Math to solve these problems. Lastly, we can hopefully help them discover the beauty of the engineering profession and guide them to choose the right field of Engineering.

With these new ideas the committee started in the early 2013 Spring Semester to redesign the entire EDGE program. The high school juniors and seniors remain the student target population but due to the vast diversity in students' Math preparedness it has been decided to make it a two year summer program. During the first summer the students will be focused primarily on Math to make them ready at least for College Algebra, enroll them in a student development class and expose them to a variety of STEM activities and field trips to make them familiar with the Engineering profession. For the second year The EDGE program will take the returning students to a higher level of Math while enrolling them in the Intro to Engineering class and involve them in more STEM activities and more field trips. We plan to rotate the field trips every other year in order to have different visits in both EDGE years.

One of the best ideas was to involve the Math department early in the planning process. This way we could tailor the math courses to fit the needs of the applying students. As a result the following changes have been implemented:

- Students will be admitted to the EDGE program based on their Accuplacer ${ }^{19}$ scores, since Accuplacer is the primary evaluation and placement tool utilized by the college:

○ Low group - score 50-69 (Math 0302 - Elementary Algebra, placement requirement)

○ Medium group - 70+ (Math 0303 - Intermediate Algebra or higher placement requirement)

- All students will be grouped together for the math module portion of the program and separated into 2 groups for STEM activities (based on Accuplacer scores and the $\mathrm{ALEKS}^{20}$ EDGE Math initial assessment results)

- The EDGE math program (3 hours/day) will use ALEKS, the online math assessment and learning system (ALEKS) which is also used for the P.A.S.S. program (Prep for Accuplacer Student Success, a special summer program to help students improve their math placement score).

○ The supervising professor will create remedial algebra (MATH 0302/0303) and college algebra modules for students (Includes 5 modules (objectives): geometry, measurements, beginning algebra (Math 0302), intermediate algebra (Math 0303), and college algebra (Math 1414). The syllabus is presented in Appendix 2.

○ Students that master Math 0303 topics (80\% level) will get credit for Math 0303.

- EDGE students will take an initial ALEKS assessment test to determine their math placement and learning goals. 
- Students that work diligently and complete the College Algebra modules with $80 \%$ mastery will be registered for on-line College Algebra in the fall and receive credit for College Algebra.

- Students that qualify for higher Math courses will be enrolled in those courses along with regular college students.

\section{Results}

From the beginning the team set up a schedule to participate in as many high school functions in our area. In total there were two visits to Region 20 to meet high school science and math teachers, 17 high schools career night visits, two youth conferences, and multiple classroom presentations to advertise our program. In some of these events MESA volunteers participated as well to engage students directly to discuss engineering careers and the EDGE program. These efforts helped bring the enrollment to 24 students.

\begin{tabular}{|r|c|c|c|c|}
\hline Grade Level & $9^{\text {th }}$ & $10^{\text {th }}$ & $11^{\text {th }}$ & $12^{\text {th }}$ \\
\hline \# Students Enrolled & 3 & 9 & 9 & 3 \\
\hline
\end{tabular}

Table 2. Total Enrollment by Grade Level for EDGE 2013

\begin{tabular}{|l|c|c|c|c|c|c|l|} 
& $\begin{array}{l}\text { MATH } \\
\mathbf{0 3 0 0}\end{array}$ & $\begin{array}{l}\text { MATH } \\
\mathbf{0 3 0 1}\end{array}$ & $\begin{array}{l}\text { MATH } \\
\mathbf{0 3 0 2}\end{array}$ & $\begin{array}{l}\text { MATH } \\
\mathbf{0 3 0 3}\end{array}$ & $\begin{array}{l}\text { Math 1414 } \\
\text { College } \\
\text { Algebra }\end{array}$ & $\begin{array}{l}\text { Math 2413 } \\
\text { Calculus }\end{array}$ & $\begin{array}{l}\text { No } \\
\text { Score }\end{array}$ \\
\hline $\begin{array}{l}\text { \# Students } \\
\text { Accuplacer } \\
\text { Scores }\end{array}$ & 7 & 1 & 4 & 1 & 8 & 2 & 1 \\
\hline
\end{tabular}

Table 3. Student Math Accuplacer Placement Scores for Developmental Math EDGE SU 2013. All Students enrolled into Math 0302

\begin{tabular}{|l|l|l|l|}
\hline & Math 0302 & $\begin{array}{l}\text { Math 1414 } \\
\text { College Algebra } \\
\text { (Pre-Calculus track) }\end{array}$ & $\begin{array}{l}\text { Math 2413 } \\
\text { Calculus }\end{array}$ \\
\hline \# Students Enrolled & 14 & 8 & 2 \\
\hline \# Students earned credit & $10 *$ & $9 * *$ & 2 \\
\hline
\end{tabular}

Table 4. Student Math Enrollment EDGE SU 2013 
*The four students that did not earn credit for Math 0302 had Accuplacer scores at or below Math 0300. While they did not gain credit for Math 0302, they mastered an average 124.5 ALEKS topics during the EDGE program. They were also given until mid-November to complete ALEKS program to gain credit for Math 0302, if they do not complete these topics they will be withdrawn from the class ("W") so that it does not affect their college-level GPA.

**One student enrolled in MATH 1414-College Algebra did not receive credit and was given the same opportunity as the student in MATH 0302 to complete the program by mid-November. Two students enrolled in Math 0302, worked at a faster pace and completed the objective modules for both MATH 0302 and Math 1414, and received credit for both math courses.

The Student Development class had only 20 students enrolled since four have earned dual credit for it through their high school program.

\begin{tabular}{|c|c|}
\hline & SDEV \\
\hline \# Students Enrolled & $\mathbf{2 0}$ \\
\hline \# Students Completed Course with an "A" & 19 \\
\hline \# Students Completed Course with a "B" & 1 \\
\hline Total \# of students who earned credit for SDEV & $\mathbf{2 0}$ \\
\hline
\end{tabular}

Table 5. Student SDEV Enrollment EDGE SU 2013

The EDGE 2013 program had four field trips that included San Antonio Water System, Boeing, Precision Molding and Tools Company, and Toyota. The field trips allowed the students to interact with the engineers and technicians working in those companies and gain an insight of what kind of work they can expect to perform if they graduate with a degree in engineering.

The STEM activities planned as team activities and for this year included "Summer Solstice/Sun Measurements", "Engineering Math and Electrical Circuits", "Fuel Cell Cars", "Air-launched Rockets", and "Sumobot Competition". They were in general well received and being team oriented activities they helped the students expand their cooperation and teamwork skills.

During the afternoon activities several STEM presentations were scheduled in the MESA Center. Some of them were made by STEM professionals to describe to EDGE students their work and help them make the connection between school classes and the real life of an engineering career. Other presentations were made by other STEM students involved in our own undergraduate research program describing their work and providing insights into various STEM projects that were going on at the same time.

Appendix 1 shows the results of the final student survey in which the students were asked to evaluate the entire program as well as each activity associated with it. 


\section{Conclusions}

Although the extensive range of students' mathematics skill development continues to be a challenge, the online self-paced learning modules were productive and well received. Another recurring theme is the popularity of the robotics activities. Our goals of dispelling the "fear of math" and increasing students' awareness of the engineering profession appear to have been met to a large extent. Only one student disagreed with the statement "I am good at math", and the majority reported being knowledgeable about engineering (and about half went on to express interest in an engineering career). All but one student agreed or agreed strongly that they were more knowledgeable of college life.

Based on the data and responses from the 2013 program, we plan to continue the entry level program in 2014 and introduce the second stage EDGE Program for returning students and those qualifying for the higher levels of Math. A new variable for the 2014 program is a recent reorganization of developmental Math classes which reduced four remedial levels to three.

\begin{tabular}{|l|l|}
\hline Basic Mathematics (MATH 0300) & Pre-Algebra (MATH 0305) \\
\hline Introduction to Algebra (MATH 0301) & \\
\hline Elementary Algebra (MATH 0302) & Elementary Algebra (MATH 0310) \\
\hline Intermediate Algebra (MATH 0303) & Intermediate Algebra (MATH 0320) \\
\hline
\end{tabular}

The new EDGE 2014 Program is planned to follow the overall configuration shown below.

The first year component (EDGE 1) will be offered to all students that apply for the first time to the EDGE program and are entering high school grades 10,11, and 12. They will be enrolled in the appropriate Math course following the recommendations of the new $\mathrm{TSI}^{21}$ assessment test. The MATH 0305 and MATH 0310 will be ALEKS based classes supported by an EDGE faculty member. Students that qualify for higher math levels will be enrolled in regular Summer 1 math classes with other non-EDGE college students. Once the math classes are over the students return to their regular daily EDGE program that includes the SDEV class and STEM activities and field trips planned for first year.

The second year component (EDGE 2) will be offered to all returning students from the first year of the new EDGE 1 (2013) and to the new students that graduated from high school and are ready for college. The returning students will be enrolled in the math level course that follows the one they passed in the previous EDGE year. The freshly high school graduates will be enrolled in the math course recommended by TSI as shown in the list of courses. The ones that graduated high school but are below college algebra go to EDGE 1. The MATH 0310 will be an ALEKS based class supported by an EDGE faculty. The students that qualify for higher math levels will be enrolled in regular Summer 1 math classes with other non-EDGE college students. Once the math classes are over the students return to their regular daily EDGE 2 program that includes the ENGR 1201 - Intro to Engineering class, a more advanced set of STEM activities, and new field trips planned for the second year. 
The planned new structure of the EDGE 2014:

EDGE 1

- MATH

- MATH 0305 - Pre-Algebra

- MATH 0310 - Elementary Algebra

- MATH 1414 - College Algebra

- MATH 2412 - Pre-calculus

- MATH 2413 - Calculus I

- SDEV

- STEM Activities

- $\quad$ Field Trips
EDGE 2

- MATH

- MATH 0310 - Elementary Algebra

- MATH 1414 - College Algebra

- MATH 2412 - Pre-calculus

- MATH 2413 - Calculus I

- MATH 2414 - Calculus II

- ENGR 1201 - Intro to Engineering

- Advanced STEM Activities

- More Field Trips

As in previous years, we remain indebted to the other members of our EDGE Executive Team, the program faculty, and our college administration. Their participation and support has enabled us to continue offering this program, and to make continuing improvements to help increase the number of high school students entering college with the intention and capability of achieving a degree in Engineering, Science, or Mathematics. 


\section{References:}

1. Getting an EDGE in Engineering Education, by Jerry O'Connor and Dan G. Dimitriu, ASEE Conference, Salt Lake City, UT, June 2004

2. PREP - Pre-Engineering Program at UTSA, URL: < www.prep-usa.org/portal/texprep/ >

3. A Strategy for Success: The EDGE Program in the Second Year, by Dan G. Dimitriu and Jerry O'Connor, ASEE Conference, Portland, OR, June 2005

4. The EDGE Summer Program in its Third Year, by Dan G. Dimitriu and Jerry O'Connor, ASEE Conference, Chicago, IL, June 2006

5. The Evolution of the EDGE Program in its Fourth Year, by Dan G. Dimitriu and Jerry O'Connor, ASEE Conference, Honolulu, HI, June 2007

6. The Fifth Year of the EDGE Program - A New Beginning, by Dan G. Dimitriu and Jerry O'Connor, ASEE Conference, Pittsburgh, PA, June 2008

7. EDGE 2008 Program - The First Signs of Maturity, by Dan G. Dimitriu and Jerry O'Connor, ASEE Conference, Austin, TX, June 2009

8. Minority Introduction to Engineering and Science (MITES) at MIT, URL: < http://engineering.mit.edu/programs/mites >

9. Summer Engineering Exploration Camp at University of Michigan, URL: < http://swe.engin.umich.edu/SEEcamp >

10. Engineering Innovation at John Hopkins University, URL: < http://engineering-innovation.jhu.edu/program-description/ >

11. Summer Camps at UTSA, URL: < http://utsa.edu/summercamps/ $>$

12. Work in Progress: A New Role for Math in Engineering Education, by Bengt Lennartsson, ASEE/IEEE Frontiers in Education Conference, San Diego, CA, October 2006

13. The kiss of death? An alternative view of college remediation, by Adelman, C. (1998). National Crosstalk, 6(3). Retrieved from http://www.highereducation.org/crosstalk/ct0798/voices0798-adelman.shtml

14. New evidence on college remediation, by Attewell, P. A., Lavin, D. E., Domina, T., \& Levey, T. (2006). Journal of Higher Education, 77(5), 886-924.

15. Summer bridge: Improving retention rates for underprepared students, by Garcia, P. (1991), Journal of the Freshman Year Experience, 3(2), 91-105.

16. The benefits of summer bridge programs for underrepresented and low-income students, by Ackermann, S. P. (1990, April). Paper presented at the annual meeting of the American Education Research Association, Boston, MA.

17. Effectiveness of summer bridge programs in enhancing college readiness, by Kallison, J. M., Jr., \& Stader, D. L. (2012), Community College Journal of Research and Practice, 36(5), 340-357.

18. Bridging the Gap - The Developmental Summer Bridge Project, by Barnett, E. A., et al., National Center for Postsecondary Research, June 2012

19. Accuplacer, URL: 〈 https://www.accuplacer.org/cat/ >

20. $\underline{\text { ALEKS }}$, URL: < http://www.aleks.com/ $>$

21. TSI Assessment Testing, URL: < http://www.scottjwarren.com/drc/TSI_Information.html > 


\section{Appendix 1}

2013 EDGE Final Student Survey - Summary of Results

Survey Date: 18 Jul 2012

Students Completing Survey: 23

A. Multiple Choice Statements/Questions:

\begin{tabular}{|c|l|c|c|c|c|c|}
\hline$\#$ & \multicolumn{1}{|c|}{ Survey Statement } & $\begin{array}{c}\text { Strongly } \\
\text { Agree }\end{array}$ & Agree & Neutral & Disagree & $\begin{array}{c}\text { Strongly } \\
\text { Disagree }\end{array}$ \\
\hline 1 & $\begin{array}{l}\text { I am knowledgeable about the } \\
\text { EDGE Program. }\end{array}$ & 17 & 6 & 0 & 0 & 0 \\
\hline 2 & $\begin{array}{l}\text { I am knowledgeable about } \\
\text { college life. }\end{array}$ & 13 & 9 & 1 & 0 & 0 \\
\hline 3 & $\begin{array}{l}\text { I am knowledgeable about the } \\
\text { engineering profession. }\end{array}$ & 7 & 12 & 2 & 0 & 1 \\
\hline 4 & $\begin{array}{l}\text { I am interested in an } \\
\text { engineering career. }\end{array}$ & 8 & 4 & 5 & 4 & 2 \\
\hline 5 & $\begin{array}{l}\text { I am good at math. } \\
6\end{array}$ & 7 & 11 & 5 & 0 & 0 \\
\hline $\begin{array}{l}\text { I am good at science. } \\
\text { Definitely }\end{array}$ & $\begin{array}{c}\text { Highly } \\
\text { Probable }\end{array}$ & Maybe & $\begin{array}{c}\text { Not } \\
\text { Likely }\end{array}$ & $\begin{array}{c}\text { Definitely } \\
\text { No }\end{array}$ \\
\hline 8 & $\begin{array}{l}\text { If offered, will you participate } \\
\text { in a fall semester EDGE } \\
\text { Program? }\end{array}$ & 8 & 7 & 9 & 3 & 0 \\
\hline 9 & $\begin{array}{l}\text { If offered next summer, will } \\
\text { you enroll in a 2 } \\
\text { Program? }\end{array}$ & 5 & 9 & 0 & 0 \\
\hline
\end{tabular}

* Student that said they strongly disagreed with being knowledgeable about the engineering profession or interested in an engineering career would recommend the EDGE Program to another student and would definitely participate if was offered in the fall or next summer.

B. Yes/No Statements/Questions:

\begin{tabular}{|l|l|c|c|}
\hline \multicolumn{1}{|c|}{ Survey Statement } & \multicolumn{1}{|c|}{ Yes } & No \\
\hline 7 & Will you recommend the EDGE Program to other students? & 23 & 0 \\
\hline 11 & Did you gain what you wanted from this program? & 23 & 0 \\
\hline 12 & $\begin{array}{l}\text { Were the EDGE Program courses well-coordinated and } \\
\text { interconnected? }\end{array}$ & 23 & 0 \\
\hline
\end{tabular}


C. ENGR 1201 Team Projects Statements:

\begin{tabular}{|c|l|c|c|c|}
\hline$\#$ & \multicolumn{1}{|c|}{ Survey Statement } & $\begin{array}{c}\text { Strongly } \\
\text { Agree }\end{array}$ & Agree & Disagree \\
\hline 18a & Summer Solstice/Sun Measurements worthwhile & 0 & 19 & 4 \\
\hline 18b & Engineering Math Electrical Circuits worthwhile & 4 & 18 & 1 \\
\hline 18c & Fuel Cell Car worthwhile & 13 & 10 & 0 \\
\hline 18d & Air-launched Rockets worthwhile & 15 & 8 & 0 \\
\hline 18e & Measurements and conversions worthwhile & 4 & 17 & 2 \\
\hline 18f & Robotics (Sumobot) worthwhile & 18 & 5 & 0 \\
\hline 19a & MESA Student Engagement worthwhile & 14 & 9 & 0 \\
\hline 19b & Engineering Professionals session worthwhile & 10 & 13 & 0 \\
\hline 19c & LS-AMP Students and Dan Suttin worthwhile & 11 & 12 & 0 \\
\hline 21a & ALEKS over Traditional MATH & 5 & 14 & 3 \\
\hline 21b & Tutors and Instructors Helpful for ALEKS & 13 & 8 & 1 \\
\hline 21c & $\begin{array}{l}\text { Learn math faster with ALEKS than traditional } \\
\text { class }\end{array}$ & 9 & 11 & 2 \\
\hline 21d & Learned more math than expected & 14 & 7 & 1 \\
\hline
\end{tabular}

D. Summary of Responses to Statements/Questions That Required Written Comments:

\begin{tabular}{|l|c|}
\hline 10. What did you want to gain from the EDGE Program? & \# of Responses \\
\hline Knowledge in Math & 12 \\
\hline $\begin{array}{l}\text { Quick view of/basic feel for/better knowledge of } \\
\text { engineering/engineering profession/work/opportunities }\end{array}$ & 10 \\
\hline Learn about college life/how to succeed in college/college credit & 6 \\
\hline Knowledge in Science & 3 \\
\hline Robotics & 1 \\
\hline & \\
\hline $\begin{array}{l}\text { 13. Which activities, subjects, or courses would you like to see } \\
\text { included in the program? }\end{array}$ & \# of Responses \\
\hline Science Class/more science & 7 \\
\hline More fields of engineering (not just mechanical/robotic) & 2 \\
\hline More robotics & 2 \\
\hline Laser Activity & 2 \\
\hline Electives & 1 \\
\hline Speech class & 1 \\
\hline Astronomy & 1 \\
\hline Another Language class & 1 \\
\hline Computer Programing class & 1 \\
\hline More activities & 1 \\
\hline Recreation time & 1 \\
\hline Nursing/Medical Related & 1 \\
\hline
\end{tabular}




\begin{tabular}{|c|c|}
\hline 14. What did you like about the EDGE Program? & \# of Responses \\
\hline Robots & 9 \\
\hline Competitions & 4 \\
\hline MESA Center & 2 \\
\hline ALEKS & 2 \\
\hline Working in teams & 2 \\
\hline Earning Math Credit/college credit & 2 \\
\hline Everything & 2 \\
\hline Guest Speakers & 1 \\
\hline Lab Activities & 1 \\
\hline Help available whenever needed & 1 \\
\hline Good Schedule/kept busy & 1 \\
\hline Learning Math at own pace & 1 \\
\hline Boeing & 1 \\
\hline 15. What did you not like about the EDGE Program? & \# of Responses \\
\hline Nothing & 7 \\
\hline $\begin{array}{l}\text { Lots of worksheets/short time period to work on assignments/short } \\
\text { time per topic }\end{array}$ & 3 \\
\hline Started too early in the summer (no break) & 2 \\
\hline Excess Math Time & 2 \\
\hline ALEKS & 1 \\
\hline Circuit lab & 1 \\
\hline Focused mainly on mechanical engineering & 1 \\
\hline Lab instructions unclear & 1 \\
\hline Started too early in the morning & 1 \\
\hline Field Trips short & 1 \\
\hline Too Long & 1 \\
\hline No recreation time & 1 \\
\hline 16. What did you like about your instructors? & \# of Responses \\
\hline Helpful & 17 \\
\hline Were detailed and specific/good explanation/knowledgeable & 7 \\
\hline Encouraging/positive/funny & 2 \\
\hline 17. What did you not like about your instructors? & \# of Responses \\
\hline Nothing & 11 \\
\hline Not enough of tutors & 6 \\
\hline High expectation of high school underclassmen & 2 \\
\hline Rushed through material & 1 \\
\hline Used unfamiliar terminology & 1 \\
\hline
\end{tabular}




\begin{tabular}{|l|c|}
\hline $\begin{array}{l}\text { 21e. What did you like most about the ALEKS EDGE Math } \\
\text { Program? }\end{array}$ & \# of Responses \\
\hline At own pace/move quickly/advanced more than expected & 9 \\
\hline Worked on things difficult for me to understand & 4 \\
\hline Learned a lot of Math & 3 \\
\hline Didn't do most of it/Didn't use ALEKS/did little ALEKS & 1 \\
\hline Different categories of math & 1 \\
\hline It's online & \\
\hline & \# of Responses \\
\hline $\begin{array}{l}\text { 21f. What did you like least about the ALEKS EDGE Math } \\
\text { Program }\end{array}$ & 8 \\
\hline Nothing & 5 \\
\hline Length/Length of the assignments/bring the \# of objects down & 2 \\
\hline Trouble looking at computer/computer & 2 \\
\hline Questions weren't explanatory/Teaching came as a wall of text & 1 \\
\hline Small errors reversed progress & 1 \\
\hline No Trio time & 1 \\
\hline Didn't use ALEKS & 1 \\
\hline Didn't know objective pie/rushed to pass & \\
\hline
\end{tabular}

E. Summary of Students' Preferences:

\begin{tabular}{|l|c|c|c|c|c|c|}
\hline & $\begin{array}{l}\text { Electrical } \\
\text { Circuits }\end{array}$ & $\begin{array}{l}\text { Summer } \\
\text { Solstice }\end{array}$ & $\begin{array}{l}\text { Fuel } \\
\text { Cell Car }\end{array}$ & $\begin{array}{l}\text { Air- } \\
\text { Launched } \\
\text { Rockets }\end{array}$ & $\begin{array}{l}\text { Measurements } \\
\text { and } \\
\text { Conversions }\end{array}$ & $\begin{array}{l}\text { Robotics } \\
\text { (Sumobots) }\end{array}$ \\
\hline $\begin{array}{l}\text { 18h.Favorite } \\
\text { STEM Activity }\end{array}$ & 0 & 0 & 3 & 6 & 0 & 15 \\
\hline $\begin{array}{l}\text { 18i. Least } \\
\text { Favorite Activity }\end{array}$ & 5 & 10 & 0 & 0 & 11 & 1 \\
\hline
\end{tabular}

\begin{tabular}{|l|l|l|l|}
\hline & $\begin{array}{l}\text { MESA Student } \\
\text { Engagement }\end{array}$ & $\begin{array}{l}\text { Engineering } \\
\text { Professionals }\end{array}$ & $\begin{array}{l}\text { LS-AMP and Dan } \\
\text { Suttin }\end{array}$ \\
\hline $\begin{array}{l}\text { 19e. Favorite STEM } \\
\text { Presentation }\end{array}$ & 7 & 10 & 10 \\
\hline $\begin{array}{l}\text { 19f. Least Favorite } \\
\text { Presentation }\end{array}$ & 12 & 5 & 5 \\
\hline
\end{tabular}

\begin{tabular}{|l|l|l|l|l|}
\hline & SAWS & Boeing & $\begin{array}{l}\text { Precision } \\
\text { Molding }\end{array}$ & Toyota \\
\hline $\begin{array}{l}\text { 20b. favorite } \\
\text { field trip }\end{array}$ & 1 & 4 & 1 & 19 \\
\hline $\begin{array}{l}\text { 20c. least } \\
\text { favorite field trip }\end{array}$ & 8 & 7 & 9 & 1 \\
\hline
\end{tabular}




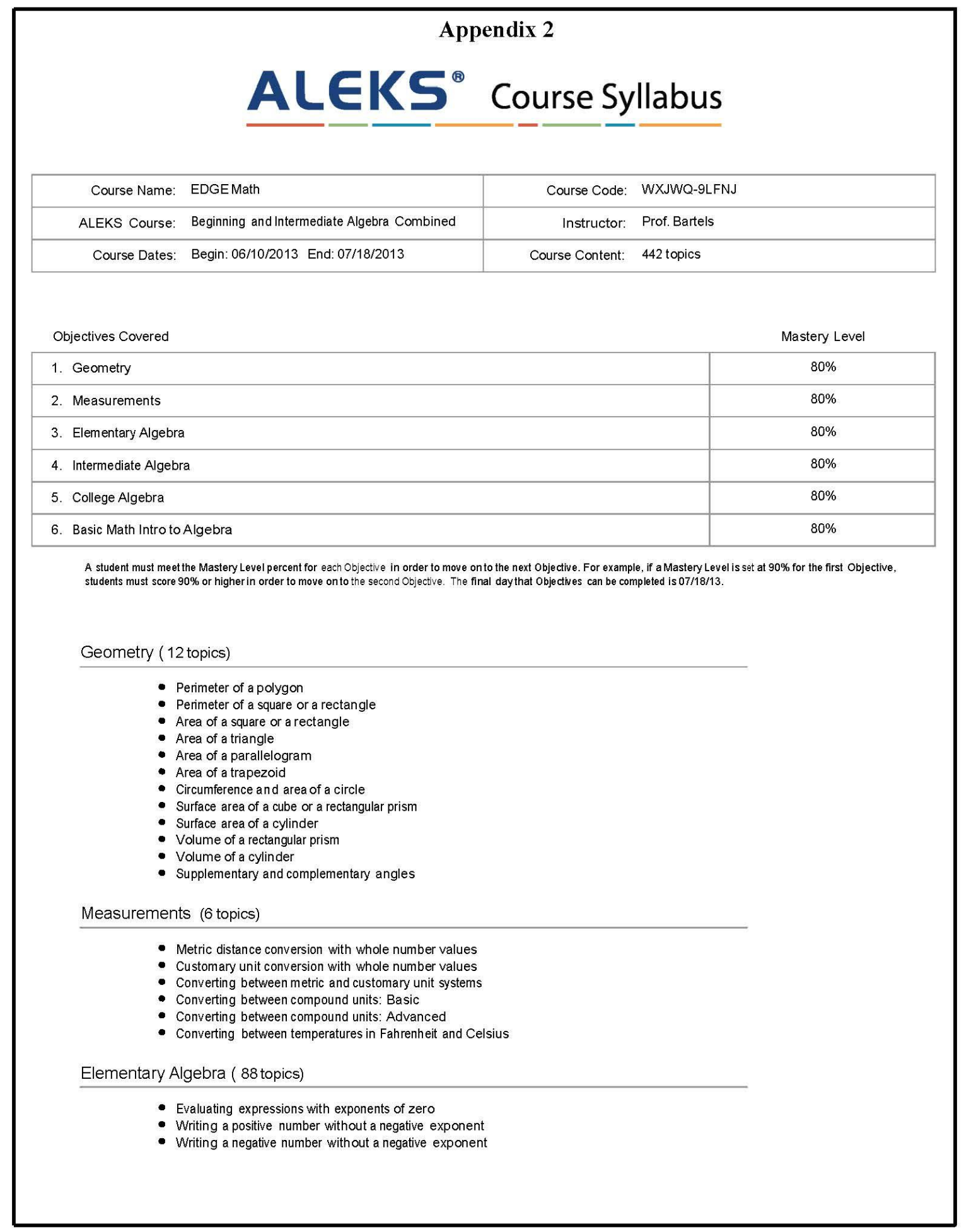

Copyright $\odot 2013$ UC Regents and ALEKS Corporation. ALEKS is a registered trademark of ALEKS Corporation. 
- Ordering numbers with positive exponents

- Ordering numbers with negative exponents

- Writing a simple algebraic expression without negative exponents

- Understanding the product rule of exponents

- Product rule with positive exponents

- Product rule with negative exponents

- Introduction to the quotient rule of exponents

- Quotients of expressions involving exponents

- Quotient rule with negative exponents: Problem type 1

- Introduction to the power rule of exponents

- Power rule with positive exponents

- Power rule with negative exponents: Problem type 1

- Power rule with negative exponents: Problem type 2

- Using the power and product rules to simplify expressions with positive exponents

Using the power, product, and quotient rules to simplify expressions with negative exponents

- Scientific notation with positive exponent

- Scientific notation with negative exponent

- Multiplying and dividing numbers written in scientific notation

- Degree and leading coefficient of a polynomial in one variable

- Degree of a multivariate polyn omial

- Simplifying a sum or difference of three univariate polynomials

- Multiplying a monomial and a polynomial: Univariate with positive leading coefficients

- Multiplying a monomial and a polynomial: Multivariate

- Multiplying binomials with leading coefficients of 1

- Multiplying conjugate binomials: Univariate

- Multiplying binomials in two variables

- Squaring a binomial: Univariate

- Multiplication involving binomials and trinomials in two variables

- Dividing a polynomial by a monomial: Univariate

- Dividing a polynomial by a monomial: Multivariate

- Polynomial long division: Problem type 1

Polynomial long division: Problem type 2

- Synthetic division

- Introduction to the GCF of two monomials

- Greatest common factor of two multivariate monomials

- Factoring out a monomial from a polynomial: Univariat

- Factoring out a monomial from a polynomial: Multivariate

- Factoring a quadratic with leading coefficient 1

- Factoring a perfect square trinomial

- Factoring a quadratic with leading coefficient greater than 1

- Factoring a quadratic polynomial in two variables with leading coefficient greater than 1

- Factoring a product of a quadratic trinomial and a monomial

- Factoring a difference of squares

- Factoring with repeated use of the difference of squares formula

- Factoring a sum or difference of two cubes

- Factoring a polynomial by grouping: Problem type 1

- Factoring a polynomial by grouping: Problem type 2

- Solving equations written in factored form

- Finding the roots of a quadratic equation with leading coefficient 1

- Finding the roots of a quadratic equation with leading coefficient greater than 1

- Roots of a product of polynomials

- Solving a word problem using a quadratic equation with rational roots

Domain of a rational function

- Simplifying a ratio of polynomials: Problem type 1

- Simplifying a ratio of polynomials: Problem type 2

- Ratio of multivariate polynomials

- Multiplying rational expressions: Problem type 1

- Multiplying rational expressions: Problem type 2

- Dividing rational expressions: Problem type 1

- Dividing rational expressions: Problem type 2

- Introduction to the LCM of two monomials

- Least common multiple of two monomials

- Adding rational expressions with common denominators

- Adding rational expressions with different denominators: ax, bx

- Adding rational expressions with different denominators: Multivariate

- Adding rational expressions with different denominators: $x+a, x+b$

- Adding rational expressions with different denominators: Quadratic 
- Complex fractions without variables: Problem type 1

- Complex fractions without variables: Problem type 2

- Complex fraction: Problem type 1

- Complex fraction: Problem type 3

- Complex fraction: Problem type 4

- Solving a proportion of the form $x / a=b / c$

- Solving a proportion of the form $(x+a) / b=x / c$

- Solving a rational equation that simplifies to a linear equation: Problem type 2

- Solving a rational equation that simplifies to a linear equation: Problem type 3

- Solving a rational equation that simplifies to a linear equation: Problem type 4

- Solving a rational equation that simplifies to a quadratic equation: Problem type 1

- Solving a rational equation that simplifies to a quadratic equation: Problem type 2

- Solving a rational equation that simplifies to a quadratic equation: Problem type 3

- Word problem on proportions: Problem type 1

- Word problem on proportions: Problem type 2

- Word problem involving multiple rates

- Solving a word problem using a rational equation

- Word problem on inverse proportions

Intermediate Algebra ( 79 topics)

- Application problem with a linear function: Problem type 1

- Application problem with a linear function: Problem type 2

- Classifying systems of linear equations from graphs

- Graphically solving a system of linear equations

- Solving a simple system using substitution

- Solving a system of linear equations using elimination with multiplication and addition

- Solving a system that is inconsistent or consistent dependent

- Solving a system of 3 equations in 3 unknowns

- Interpreting the graphs of two functions

- Solving a word problem involving a sum and another simple relationship using a system of linear equations

- Solving a value mixture problem using a system of linear equations

- Solving a distance, rate, time problem using a system of linear equations

- Solving a percent mixture problem using a system of linear equations

- Solving a tax rate or interest rate problem using a system of linear equations

- Solving a word problem using a 3 by 3 system of linear equations

- Graphing a system of linear inequalities

- Solving a word problem using a system of linear inequalities

- Square root of a perfect square

- Estimating a square root

- Square root of a rational perfect square

- Cube root of an integer

- Square root simplification

- Square root of a perfect square monomial

- Simplifying a radical expression: Problem type 1

- Simplifying a radical expression: Problem type 2

- Simplifying a higher radical: Problem type 1

- Simplifying a higher radical: Problem type 2

- Square root addition

- Simplifying a sum of radical expressions

- Square root multiplication

- Simplifying a product of radical expressions

- Simplifying a product of radical expressions: Advanced

- Simplifying a product of radical expressions using the distributive property

- Special products with square roots: Conjugates and squaring

- Simplifying products or quotients of higher index radicals with different indices

- Rationalizing the denominator of a radical expression

- Rationalizing the denominator of a radical expression using conjugates

- Rationalizing the denominator of a higher index radical with variables

- Converting between radical form and exponent form

- Rational exponents: Basic

- Rational exponents: Negative exponents and fractional bases

- Rational exponents: Products and quotients

- Rational exponents: Powers of powers

- Solving a radical equation that simplifies to a linear equation: One radical

- Solving a radical equation that simplifies to a linear equation: Two radicals 
- Solving a radical equation that simplifies to a quadratic equation: One radical

- Solving a radical equation that simplifies to a quadratic equation: Two radicals

- Solving an equation with a root index greater than 2

- Pythagorean Theorem

- Using $i$ to rewrite square roots of negative numbers

- Simplifying a product or quotient involving roots of negative numbers

- Adding and subtracting complex numbers

- Multiplying complex numbers

- Dividing complex numbers

- Simplifying a power of $i$

- Evaluating functions: Problem type 1

- Evaluating functions: Problem type 2

- Identifying functions from relations

- Determining whether an equation defines a function

- Vertical line test

- Domain and range from ordered pairs

- Domain and range from the graph of a continuous function

Domain and range from the graph of a piecewise function

- Graphing a parabola of the form $y=a x^{2}$

- Solving a quadratic equation using the square root property: Problem type 1

- Solving a quadratic equation using the square root property: Problem type 2

- Completing the square

- Solving a quadratic equation by completing the square

- Applying the quadratic formula: Exact answers

- Solving a quadratic equation with complex roots

- Discriminant of a quadratic equation

- Solving a word problem using a quadratic equation with irrational roots

- Finding the x-intercept(s) and the vertex of a parabola

- Rewriting a quadratic function to find the vertex of its graph

- Range of a quadratic function

- Graphing a parabola of the form $y=(x-a)^{2}+c$

- Graphing a parabola of the form $y=a x^{2}+b x+c$ : Integer coefficients

- Graphing a parabola of the form $y=a x^{2}+b x+c$ : Rational coefficients

How the leading coefficient affects the shape of a parabola

\section{College Algebra ( 77 topics)}

- Solving an inequality involving absolute valu

- Solving an inequality involving absolute value: Basic

- Scalar multiplication of a matrix

- Addition and subtraction of matrices

- Linear combinations of matrices

- Finding the determinant of a $2 \times 2$ matrix

- Finding the determinant of a $3 \times 3$ matrix

- Cramer's rule: Problem type 1

- Cramer's rule: Problem type 2

- Gauss-Jordan elimination with a $2 \times 2$ matrix

- Augmented matrix and solution set of a system of linear equations

- Using the remain der theorem to evaluate a polynomial

- Finding the asymptotes of a rational function: Problem type 1

- Sketching the graph of a rational function: Problem type 1

- Finding intercepts and zeroes of a function given the graph

- Writing an equation for a function after a vertical translation

- Writing an equation for a function after a vertical and horizontal translation

- Translating the graph of a function: One step

- Translating the graph of a function: Two steps

- Graphing a simple cubic function

- Graphing an equation involving absolute value in the plane: Advanced

- Graphing a piecewise-defined function

- Sum, difference, and product of two functions

- Quotient of two functions

- Combining functions: Advanced

- Composition of two functions: Basic

- Composition of two functions: Domain and range

- Composition of two functions: Advanced 
- Expressing a function as a composition of two functions

- Horizontal line test

- Determining whether two functions are inverses of each other

- Inverse functions: Problem type 1

- Inverse functions: Problem type 2

- Inverse functions: Problem type 3

- Writing the equation of a quadratic function given its graph

- Converting between logarithmic and exponential equations

- Converting between natural logarithmic and exponential equations

- Evaluating a logarithmic expression

- Basic properties of logarithms

- Writing expressions as a single logarithm

- Expanding a logarithmic expression: Problem type 1

- Expanding a logarithmic expression: Problem type 2

- Change of base for logarithms: Problem type 1

- Change of base for logarithms: Problem type 2

- Solving a logarithmic equation: Problem type 1

- Solving a logarithmic equation: Problem type 2

- Solving a logarithmic equation: Problem type 3

- Solving a logarithmic equation: Problem type 4

- Solving a logarithmic equation: Problem type 5

- Solving an exponential equation: Problem type 1

- Solving an exponential equation: Problem type 2

- Solving an exponential equation: Problem type 3

- Evaluating an exponential function that models a real-world situation

- Solving a word problem using an exponential equation: Problem type 1

- Solving a word problem using an exponential equation: Problem type 2

- Solving a word problem using an exponential equation: Problem type 3

- Solving a word problem using an exponential equation: Problem type 4

- Compound interest

- Sketching the graph of an exponential function: Basic

- The graph, domain, and range of an exponential function

- Sketching the graph of an exponential function: Advanced

- Sketching the graph of a logarithmic function: Basic

- The graph, domain, and range of a logarithmic function

- Sketching the graph of a logarithmic function

- Translating the graph of a logarithmic or exponential function

- Graphing a parabola with a horizontal or a vertical axis

- Writing an equation of a parabola given the vertex and the focus

- Finding the focus of a parabola

- Finding the first terms of a sequence

- Arithmetic sequences

- Geometric sequences

- Arithmetic and geometric sequences: Identifying and writing in standard form

- Sum of the first $n$ terms of an arithmetic sequence

- Sum of the first $n$ terms of a geometric sequence

- Sum of a geometric series

- Factorial expressions

- Binomial formula

Basic Math Intro to Algebra (180 topics)

- Introduction to exponent

- Writing expressions using exponents

- Order of operations: Problem type 1

- Order of operations: Problem type 2

- Order of operations with whole numbers and exponents: Basic

- Factors

- Prime numbers

- Prime factorization

- Greatest common factor

- Least common multiple

- Word problem with common multiples

- Simple word problem on proportions

- Equivalent fractions

- Simplifying a fraction 
- Ordering fractions

- Addition or subtraction of fractions with the same denominato

- Addition or subtraction of fractions with different denominators

- Fractional part of a circle

- Product of a unit fraction and a whole number

- Product of a fraction and a whole number

- Introduction to fraction multiplication

- Fraction multiplication

- The reciprocal of a number

- Division involving a whole number and a fraction

- Fraction division

- Mixed arithmetic operations with fractions

- Word problem with fractions

- Writing an improper fraction as a mixed number

- Writing a mixed number as an improper fraction

- Addition of mixed numbers with same denominator and carry

- Subtraction of mixed numbers with same denominator and borrowing

- Addition or subtraction of mixed numbers with different denominators

- Mixed number multiplication: Problem type 1

- Mixed number division

- Decimal place value

- Rounding decimals

- Converting a decimal to a fraction: Advanced

- Converting a fraction to a terminating decima

- Converting a fraction to a repeating decimal

- Converting a mixed number to a decimal

- Multiplication of a decimal by a power of ten

- Multiplication of a decimal by a whole number

- Decimal multiplication: Problem type 1

- Division of a decimal by a power of ten

- Division of a decimal by a whole number

- Decimal division

- Word problem with one decimal operation: Problem type 1

- Word problem with one decimal operation: Problem type 2

- Word problem using decimal addition and multiplication

- Word problem using decimal subtraction and division

- Converting between percentages and decimals

- Converting a percentage to a fraction

- Converting a fraction to a percentage

- Writing a ratio as a percentage

- Computing a percentage from a table of values

- Percentage of a whole number

- Applying the percent equation

- Finding the sale price given the original price and percent discount

- Finding the original price given the sale price and percent discount

- Finding the percentage increase or decrease

- Computations from circle graphs

- Simple interest

- Ordering integers

- Plotting integers on a number line

- Fractional position on a number line

- Plotting rational numbers on a number line

- Integer addition: Problem type 1

- Integer addition: Problem type 2

- Integer subtraction: Problem type 1

- Integer subtraction: Problem type 2

- Integer subtraction: Problem type 3

- Signed fraction addition: Basic

- Signed fraction addition: Advanced

- Signed decimal addition with three numbers

- Integer multiplication and division

- Multiplication of 3 or 4 integers

- Signed fraction multiplication: Basic

- Signed fraction multiplication: Advanced

- Mixed arithmetic operations with integers

- Exponents and integers: Problem type 1

- Exponents and integers: Problem type 2 
- Exponents and signed fractions

- Exponents and order of operations

- Evaluating a linear expression in two variables

- Evaluating a quadratic expression in one variable

- Absolute value of a number

- Operations with absolute value

- Integers and rational numbers

- Rational and irrational numbers

- Distributive property: Whole number coefficients

- Distributive property: Integer coefficients

- Combining like terms: Whole number coefficients

- Combining like terms: Integer coefficients

- Combining like terms: Advanced

- Combining like terms in a quadratic expression

- Properties of addition

- Properties of real numbers

- Additive property of equality with whole numbers

- Additive property of equality with fractions and mixed numbers

- Additive property of equality with decimals

- Additive property of equality with integers

- Additive property of equality with a negative coefficient

- Multiplicative property of equality with whole numbers

- Multiplicative property of equality with fractions

- Multiplicative property of equality with decimals

- Multiplicative property of equality with integers

- Multiplicative property of equality with signed fractions

- Using two steps to solve an equation with whole numbers

- Solving a two-step equation with integers

- Solving a two-step equation with signed fractions

- Using two steps to solve an equation with signed decimals

- Solving an equation to find the value of an expression

- Solving a linear equation with several occurrences of the variable: Variables on the same side and distribution

- Solving a linear equation with several occurrences of the variable: Variables on both sides and fractional coefficients

- Solving a linear equation with several occurrences of the variable: Variables on both sides and distribution

- Solving a linear equation with several occurrences of the variable: Variables on both sides and two distributions

- Solving a linear equation with several occurrences of the variable: Fractional forms with binomial numerators

- Solving equations with zero, one, or infinitely many solutions

- Introduction to algebraic symbol manipulation

- Algebraic symbol manipulation: Problem type 1

- Algebraic symbol manipulation: Problem type 2

- Writing a signed number for a real-world situation

- Word problem with addition or subtraction of integers

- Writing a one-step variable expression for a real-world situation

- Translating a sentence into a two-step expression

- Translating a sentence into a one-step equation

- Writing a multi-step equation for a real-world situation

- Solving a fraction word problem using a linear equation of the form $A x=B$

- Solving a word problem with two unknowns using a linear equation

- Solving a decimal word problem using a linear equation with the variable on both sides

- Solving a decimal word problem using a linear equation of the form $A x+B=C$

- Solving a fraction word problem using a linear equation with the variable on both sides

- Solving a word problem with three unknowns using a linear equation

- Solving a value mixture problem using a linear equation

- Solving a percent mixture problem using a linear equation

- Finding unit rates

- Solving a simple word problem using the formula $d=r t$

- Solving a word problem involving rates and time conversion

- Solving a distance, rate, time problem using a linear equation

- Translating a sentence into a simple inequality

- Graphing a linear inequality on the number line

- Writing an inequality given a graph on the number line

- Writing a compound inequality

- Graphing a compound linear inequality on the number line

- Solving a linear inequality: Problem type 1

- Solving a linear inequality: Problem type 2

- Solving a linear inequality: Problem type 3

- Solving a linear inequality: Problem type 4 
- Solving a linear inequality: Problem type 5

- Solving a compound linear inequality: Problem type 1

- Solving a compound linear inequality: Problem type 2

- Writing a simple inequality for a real-world situation

- Writing a multi-step in equality for a real-world situation

- Word problem with linear inequalities: Problem type 1

- Word problem with linear inequalities: Problem type 2

- Reading a point in the coordinate plane

- Plotting a point in the coordinate plane

- Tables for linear functions

- Finding a solution to a linear equation in two variables

- Identifying solutions to linear equations in two variables

- Graphing a line given the $x$ - and $y$-intercepts

- Graphing a line given its equation in slope-intercept form

- Graphing a line given its equation in standard form

- Graphing a line through a given point with a given slope

- Graphing a vertical or horizontal line

- Y-intercept of a line

- Finding $x$ - and $y$-intercepts of a line given the equation: Advanced

- Finding slope given the graph of a line on a grid

- Finding slope given two points on the line

- Finding the slope of a line given its equation

- Writing an equation of a line given the $y$-intercept and another point

- Writing the equation of a line given the slope and a point on the line

- Writing the equation of the line through two given points

- Writing the equations of vertical and horizontal lines through a given point

- Writing an equation and drawing its graph to model a real-world situation

- Slopes of parallel and perpendicular lines: Problem type 1

- Slopes of parallel and perpendicular lines: Problem type 2

- Graphing a linear inequality in the plane: Standard form

- Graphing a linear inequality in the plane:Vertical or horizontal lines

- Graphing a linear inequality in the plane: Slope-intercept form 